\title{
Anticancer Effects of Urtica Dioica in Breast Cancer
}

\author{
Percin Karakol ${ }^{1 *}$, Serpil Unver Saraydin ${ }^{2}$, Mehmet Bozkurt ${ }^{1}$, Ceylan Hepokur ${ }^{3}$, \\ Zeynep Deniz Sahin Inan², Mustafa Turan ${ }^{4,5}$
}

\begin{abstract}
Objective: The goal of this study is to look into the antiproliferative capabilities of Urtica Dioica (UD) on breast cancer. Methods: The cytotoxicity of UD extracts against breast cancer cell lines was investigated. Flow cytometry analyses were used to investigate in vitro apoptosis of breast cancer cells using Annexin V labeling. In vivo tests also performed. Results: UD showed cytotoxicity to three cancer cell lines. The number of Annexin-positive cells was higher in UD-treated cell lines than in untreated control cells. When compared to the untreated control group, the rats treated with UD had greater expressions of caspase 3, p53 protein, and TUNEL positive cells. When compared to the control group, Ki-67 expression was reduced in the treatment groups. In vivo tests revealed that, when compared to untreated rats, the mean tumor volume inhibition ratio in the UD group was 38 percent. Conclusion: These findings suggest that Urtica Dioica may have antitumoral properties in the treatment of breast cancer.
\end{abstract}

Keywords: Urtica Dioica- breast cancer- anticancer- in vitro- cytotoxicity

Asian Pac J Cancer Prev, 23 (2), 673-681

\section{Introduction}

Breast cancer is the most common cancer in women, and it is also one of the leading causes of mortality globally. A multidisciplinary strategy is presently used in the treatment of breast cancer. Several new research has recommended several novel therapeutic targets for adjuvant, complementary, and alternative medications, including natural goods bioactivity from plants, to treat breast cancer patients.

Urtica Dioica belongs to the Urticaceae family of perennial herbs. When a nettle's caustic hair is touched, acetylcholine, histamine, and 5-hydroxytryptamine (serotonin) are released. Potassium salts, vitamin C, polysaccharides, lignans, formic acid, high quantities of chlorophyll, flavonoids, sterols, enzymes, phenylpropanes, coumarins, and terpenoids are all found in dead Urtica Dioica (Gözüm et al., 2003). Nettle contains quercetin-3-O-glucoside, kaempherol-3-O-rutinoside, and isorhamnetin-3-O-glucoside in the above-ground section (Akbay et al., 2003). The flower of U. Dioica is high in phenols and flavonoids (Mandal et al., 2009). Antihyperglycemic (El Haouari et al., 2006), antimicrobial, antibacterial, antifungal (Kan et al., 2009), antioxidant (Toldy et al., 2009), anti-inflammatory (Martinez et al., 2005), antiproliferative (Abu-dahab et al., 2007), antiallergic (Roschek et al., 2009), and anticancer like multiple biological activities are involved in Urtica Dioica. Urtica dioica has traditionally been used in the control of cardiovascular disorders especially hypertension. The leaf extract of Urtica dioica has been reported to improve glucose homeostasis in vivo. Nettle root could prevent some of the effects of prostatic hyperplasia. Extracts of nettle leaf are used as anti-inflammatory remedies for rheumatoid arthritis. Urtica dioica extract significantly increased the sensitivity of breast cancer cells to paclitaxel (Dhouibi et al., 2019). Francišković et al., (2017) reported that Urtica dioica L. is a candidate for the development of phytopharmaceuticals or dietary supplements for cotreatment of various inflammatory diseases, particularly inflammatory bowel diseases.

Saponaro et al., (2020) reported that Urtica dioica and Serenoa repens combination hava promising role in Benign Prostate Hyperplasia and BPH-linked disorder prevention. Esposito et al., (2019) reported anti-proliferative and apoptotic effects of U. dioica on different human cancers. They proposed that these effects of U. dioica extracts are due to its bioactive natural products content, including polyphenols which reportedly possess anti-oxidant, anti-mutagenic and anti-proliferative properties (Esposito et al., 2019).

Mansoori et al., (2017) reported that Urtica dioica extract could inhibit cancer cell migration by regulating miR-21, MMP1, MMP9, MMP13, vimentin, CXCR4,

${ }^{1}$ Plastic Reconstructive and Aesthetic Surgery, Health Science University, Bagcilar Education and Training Hospital, Istanbul, Turkey. ${ }^{2}$ Department of Histology and Embryology, Faculty of Medicine, Cumhuriyet University, Sivas, Turkey. ${ }^{3}$ Department of Plastic Surgery, Health Science University, Istanbul, Turkey. ${ }^{4}$ Department of Biochemistry, Faculty of Pharmacy, Cumhuriyet University, Sivas, Turkey. ${ }^{5}$ Department of General Surgery, Health Science University, Istanbul, Turkey. *For Correspondence: ppercin@gmail.com 
and E-Cadherin. Moreover, their findings demonstrated that the extract could decrease miR-21 expression, which substantially lessens the overexpressed metastasis-related genes MMP1, MMP9, MMP13, vimentin, and CXCR4 and increases E-cadherin in the tumoral group. Fattahi et al., (2013) also reported in vitro antiproliferative effect of aqueous extract of Urtica dioica on breast cancer cell line MCF-7.

Urtica Dioica has also been demonstrated to have chemo preventive qualities against certain carcinogens (Tello et al., 2008; Wollowski et al., 2001). In this study, antitumoral effects of Urtica Dioica on breast cancer were examined in vitro and in vivo.

\section{Materials and Methods}

Collection and Preparation of the Urtica Dioica extracts Urtica Dioica was obtained in its natural environment in the Gurun region of the province of Sivas, Turkey. UD washed in distilled water and dried for two weeks in the lab. Following the grinding of dried samples, $100 \mathrm{~g}$. of UD plant leaf was placed in $1,000 \mathrm{~mL}$ water and sonicated for 45 minutes at $45^{\circ} \mathrm{C}$ in an ultrasonic bath, twice. It was then evaporated at $30^{\circ} \mathrm{C}$ using a rotary evaporator. The extract was kept at $-20^{\circ} \mathrm{C}$ until it was ready to be used.

\section{Reagents and drugs}

Dulbecco's modified Eagles medium (DMEM), Fetal bovine serum (FBS), and $2.5 \%$. trypsin was purchased from Sigma-Aldrich St. Louis, MO, USA.

\section{Cell cultures}

MDA-MB-231 was graciously supplied by Dr. Uygar Tazebay, Ankara, Turkey, and two human breast cancer cell lines (MCF-7, MDA-MB-468) were bought from Sap Institute, Ankara, Turkey. The medium utilized in our experiment was DMEM with $10 \%$ fetal bovine serum (FBS), 1\% L-glutamine, and 1\% penicillin-streptomycin. MCF-7, MDA-MB-231, and MDA-MB-468 cell lines were grown in DMEM at $37^{\circ} \mathrm{C}$ in an incubator with $5 \%$ $\mathrm{CO}_{2}$. Mycoplasma testing has been done for in vitro model system.

\section{Cytotoxicity assay}

The cytotoxic effect of UD extracts on MCF7, MDA-MB-468 and MDA-MB-231 cells. was determined using the trypan blue dye exclusion test (Roomi et al., 2011) and 3-(4,5-dimethylthiazol-2-yl)-2, diphenyltetrazolium bromide (MTT) proliferation assay. For MTT assay; first, tumor cells were seeded into 96- well tissue culture plates. After an attachment period of $6 \mathrm{~h}$ at $37^{\circ} \mathrm{C}$ in a $5 \% \mathrm{CO}_{2}$ humidified incubator, the cells were treated with fresh medium alone or medium containing UD extracts at various concentrations $(\mu \mathrm{g} / \mathrm{mL})$ for $48 \mathrm{~h}$. During the last $2 \mathrm{~h}$ of incubation, $40 \mu \mathrm{L}$ MTT $(2.5 \mathrm{mg} /$ $\mathrm{mL}$; Sigma) was added into each well $(0.42 \mathrm{mg} / \mathrm{mL})$. At the end of the incubation, the MTT was removed and the cells were lysed with dimethylsulfoxide. Metabolically viable cells were monitored for conversion of MTT to formazan using a Multiskan FC 96-well microtiter plate reader at $570 \mathrm{~nm}$ (Thermo Scientific, MA, USA). The level of cytotoxicity was calculated using the following formula: cytotoxicity $(\%)=(\mathrm{A}-\mathrm{B} / \mathrm{A}) \times 100$, in which $\mathrm{A}$ is the $570-\mathrm{nm}$ absorbance of cells treated with medium alone and $\mathrm{B}$ is the $570-\mathrm{nm}$ absorbance of cells treated with UD extracts.

Paclitaxel was used as positive control. All experiments were performed in triplicate

Apoptosis assay of in vitro studies of $M C F-7, M D A-M B$ 468 and $M D A-M B-231$ cells

Flow cytometry with Annexin-V labeling was used to investigate whether UD extracts promoted apoptosis in MCF-7, MDA-MB-468, and MDA-MB-231 cells. Phosphatidyl serine is exposed at the cell's exterior surface during early stages of apoptosis, and Annexin-V can detect it. Propidium Iodide (PI) positivity can also be found in late apoptotic and necrotic cells. Living cells, however, will show neither Annexin-V nor PI positivity.

Briefly, MCF-7, MDA-MB-468 and MDA-MB-231 cells were untreated or treated for $48 \mathrm{~h}$ with UD extracts at different concentrations. As a positive control, MCF-7, MDA-MB-468 and MDA-MB-231 cells were incubated in the presence of paclitaxel.

After incubation, cells were washed twice with cold PBS and then resuspended in 1X Binding Buffer (10 $\mathrm{mM}$ Hepes, $140 \mathrm{mM} \mathrm{NaCl}, 2.5 \mathrm{mM} \mathrm{CaCl} 2, \mathrm{pH}$ [7.4]) at a concentration of $1 \times 10^{6}$ cells $/ \mathrm{mL}$. Then $100 \mu \mathrm{l}$ of the solution $\left(1 \times 10^{5}\right.$ cells $)$ transferred to a $5 \mathrm{ml}$ culture tube and $5 \mu \mathrm{l}$ of annexin V-FITC and $5 \mu \mathrm{l}$ Propidium Iodide added and incubated for $15 \mathrm{~min}$ at room temperature $\left(25^{\circ} \mathrm{C}\right)$ in the dark.Later $400 \mu \mathrm{l}$ of $1 \mathrm{X}$ Binding Buffer was added to each tube and analyzed by flow cytometry (Becton Dickinson FACS Calibur, Heidelberg, Germany) within $1 \mathrm{hr}$. All analyses were performed with CellQuest software (Becton Dickinson).

\section{In Vivo Tumor Volume Studies}

A total of 14 female albino Wistar rats $(180 \pm 15$ g) 50-59 days old maintained in Animal Laboratory of Health Science University Faculty of Medicine, Bagcilar Education and Training Hospital. Animals were kept at temperature $24 \pm 2^{\circ} \mathrm{C}$ with a 12 hour light/dark cycle and $60 \% \pm 5 \%$ humidity. They were given a standard pellet diet and unlimited water. The experiment was carried out with the 2017/103 approval code, in accordance with the guidelines of the Ethics Committee for the Control and Supervision of Experiments on Animals, Health Sciences University Bagcilar Education and Training Hospital.

All of the rats were divided into two groups, each with seven rats. Rats in Groups I and II developed mammary carcinogenesis after receiving a single subcutaneous injection of $25 \mathrm{mg}$ DMBA in a $1 \mathrm{~mL}$ emulsion of sesamoid oil $(0.75 \mathrm{~mL})$ and physiological saline $(0.25 \mathrm{~mL})$ in the right pectoral area. During the experiment, the animals were weighed once a week. Every day, the animals were checked to see what their health condition is.

After DMBA administration, the right pectoral area of all rats was examined for tumor development. Palpation of mammary tumors begins 5 weeks after the animals received DMBA. Calipers were used to measure the 
volume of each tumor once every five days. Tumor volume was calculated using the formula: Tumor volume (cc) (D x $\mathrm{d} 2 \mathrm{x} \pi) / 6(\mathrm{D}=$ big diameter, $\mathrm{d}=$ small diameter $)$. The results are denominated in mean \pm Standard Error.

When the nodule reached to a mean volume of 250 $\pm 4.3 \mathrm{~mm} 3( \pm$ S.E. $)$ fine needle aspiration biopsy was performed from the nodules. Nodules reached that size mean of $8 \pm 2$ weeks. For each nodule, a relevant biopsy was used to perform a histopathological examination.

After a histopathological examination revealed breast cancer, treatment with UD extract was started in group II (Treatment Group). In Group I, no medicine was given to the control animals. In Group II, rats were given UD extract (100 mg/kg body weight) every day via oral gavage. After 6 weeks of treatment, rats in Groups I and II were sacrificed and tumors were removed from the animals. The Tumor Volume Inhibition Ratio (percent) = $[(\mathrm{A}-\mathrm{B}) / \mathrm{A}] \times 100$, where $\mathrm{A}$ is the average tumor volume of the control group and $\mathrm{B}$ is the tumor volume of the treated group.

\section{Histopathological and morphological observations}

Each tumor tissue was microscopically sampled and fixed for 24 hours in a $10 \%$ formaldehyde solution. Tumor tissues were processed in an auto technic on device, then embedded in paraffin blocks, and cut sections with 3-5 $\mu \mathrm{m}$ thickness were obtained and stained with HaemotoxylenEosin stain for routine light microscopy histopathological examination.

\section{Immunohistochemistry}

Tissues were deparaffinized and rehydrated for Ki 67, Caspase 3, p53 immunohistochemical staining. Hydrogen Peroxide Block (Thermo Scientific, TA-125-HP, USA) was then incubated for 10 minutes for endogenous peroxidase activity. Ethylene Diamine Tetra Acetic Acid (EDTA pH 8) was boiled in the microwave in a buffer solution (Thermo Scientific, 27718, USA) for 35 minutes. It was then washed several times in Phosphate buffered saline (PBS) (Sigma, SLBT7340, USA). Ultra V Block (Thermo Scientific, PBQ180830, USA) was dropped and waited for 20 minutes. Mouse Monoclonal Ki67 in the dark (Genemed Biotechnologies, CloneGM010, USA) Rabbit Polyclonal Caspase 3 (CPP32) Ab-4 (Thermo Scientific, RB-1197-R7, USA) and Mouse Monoclonal anti-P53 (Genemed Biotechnologies, Clone BP -53-12 (USA) antibodies were incubated for 1.5 hours. At the end of the period, washing was done twice with PBS. It started to incubate with Streptavidin-HRP (Thermo Scientific, USA) in the dark at $36^{\circ} \mathrm{C}$ for 20 minutes. Washing was done twice with PBS. 3,3\&\#39; Diaminobenzidine (DAB) (ScyTek, USA) chromogen was applied for 5 minutes. Drying and closing (Lab Vision, USA) after contrast staining with hematoxylin for 1 minute was examined under a microscope (Olympus BX51, Japan) minute, it was dried and closed (Lab Vision, USA) and examined under a microscope (Olympus BX51, Japan).

In immunohistochemistry studies the semiquantitative scoring system was used in considering the staining intensity and area extent, which has been widely accepted and used in previous studies (Han et al., 2009), Every tumor was given a score according to the intensity of the nuclear or cytoplasmic staining (no staining $=0$; weak staining $=1$; moderate staining $=2$; strong staining $=3$ ) and the extent of stained cells $(0 \%=0 ; 1-10 \%=1 ; 11-50$ $\%=2 ; 51-80 \%=3 ; 81-100 \%=4)$.

The percentage of proliferating neoplastic cells was evaluated directly by light microscopy. Quantification of the proliferation was performed by counting, Ki-67 and p53 positive cells in 4-6 random fields per slide. Caspase-3 activity was evaluated semiquantatively in the cytoplasm of the tumor cells either in living or in the necrotic tumor cell areas.

\section{In Vivo Apoptosis Assay}

The tissue with apoptotic DNA strand breaks was assessed by fluorescent labeling of terminal dUTP nickend labeling (TUNEL). A fluorometric TUNEL detection kit was used according to the manufacturer\&\#39; instructions (11684795910; Roche Applied Science, Indianapolis, IN).

Tissue sections taken at $3 \mu$ were passed through increasing ethyl alcohol series and rinsed in PBS (Sigma)

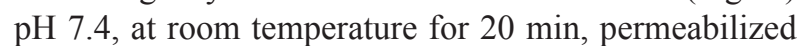
with $0.2 \%$ Triton X-100 (Sigma, St Louis, USA) in $0.1 \%$ sodium citrate (Sigma, St Louis, USA) at $4^{\circ} \mathrm{C}$ for $2 \mathrm{~min}$, and incubated with the provided fluorescein-conjugated TUNEL reaction mixture in a humidified chamber at $37^{\circ} \mathrm{C}$ for $1 \mathrm{~h}$ in the dark. Then the sections were mounted with mounting medium (Mounting medium; Thermo Scientific, Rockford, USA). TUNEL were examined under a fluorescence microscope (Biological Research Microscope BX51; Olympus, Tokyo, Japan) with equipped digital camera.

\section{Statistical analysis}

The mean standard error is used in the results report (SE). The Mann-Whitney U Test was used to assess the statistical significance of the data gathered from the experiments. Significant was defined as a p-value of less than 0.05 .

\section{Results}

MCF-7, MDA-MB-468, and MDA-MB-231 cells were treated varied concentrations of Urtica Dioica extract (5$30 \mu \mathrm{g} / \mathrm{mL}$ ) for 48 hours. The Trypan blue dye exclusion test and MTT assay was used to investigate the cell growth (Figure 1) .In the study, $\mathrm{IC}_{50}$ value of UD was calculated. The $\mathrm{IC}_{50}$ values are listed in Table 1.

These findings revealed that UD reduces the viability of MCF-7, MDA-MB-468, and MDA-MB-231 cells in a dose-dependent manner (Figure 1). Three cancer cell lines were cytotoxic to crude extracts of $\mathrm{UD}$, with $\mathrm{IC}_{50}$ values of $18 \pm 2.0 \mu \mathrm{g} / \mathrm{mL}, 17 \pm 1.4 \mu \mathrm{g} / \mathrm{mL}$, and $14 \pm 1.8 \mu \mathrm{g} /$ $\mathrm{mL}$, respectively.

\section{Cell apoptosis detection through flow cytometry}

Flow cytometry examination with Annexin-V labeling confirmed the apoptosis of MCF-7, MDA-MB-468, and MDA-MB-231 cells. These cells were untreated or treated for $48 \mathrm{~h}$ with UD with $\mathrm{IC}_{50}$ values $18 \mu \mathrm{g} / \mathrm{mL}, 17 \mu \mathrm{g} / \mathrm{mL}$, 


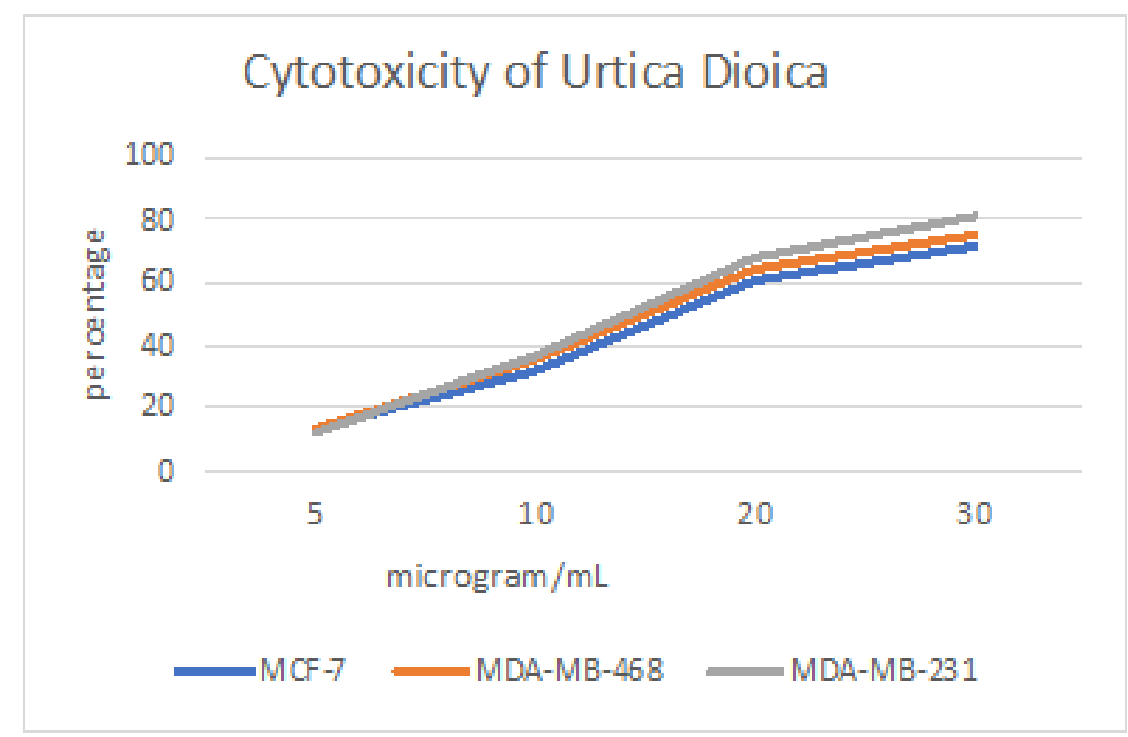

Figure 1. Urtica Dioica (UD) Cytotoxicity in MCF-7, MDA-MB-468, and MDA-MB-231 Cells. UD was used in a 48-hour incubation of target cells at various concentrations $(\mu \mathrm{g} / \mathrm{mL})$. The Trypan blue dye exclusion test and MTT proliferation test was used to determine cytotoxicity. In each group, triplicate wells were used. The mean $\pm \mathrm{SE}$ is represented by each point. ( $\mathrm{p}=0.002)$, one of at least three independent studies.

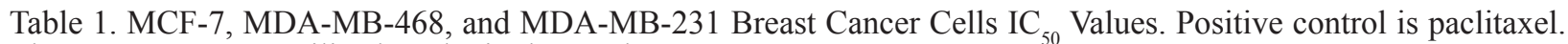
The mean \pm S.E. was utilized to obtain the results

\begin{tabular}{lccc}
\hline & MCF-7 & MDA-MB-468 & MDA-MB-231 \\
\hline Urtica Dioica & $18 \pm 2.0 \mu \mathrm{g} / \mathrm{mL}$ & $17 \pm 1.4 \mu \mathrm{g} / \mathrm{mL}$ & $14 \pm 1.8 \mu \mathrm{g} / \mathrm{mL}$ \\
Paclitaxel & $12 \pm 1.4 \mathrm{ng} / \mathrm{mL}$ & $13 \pm 2.1 \mathrm{ng} / \mathrm{mL}$ & $10 \pm 1.7 \mathrm{ng} / \mathrm{mL}$ \\
\hline
\end{tabular}

$14 \mu \mathrm{g} / \mathrm{mL}$ respectively. Percentage of Annexin-positive cells detected in treated cell lines were $21 \pm 2.3 \%$ in MCF7 cells; $23 \pm 2.3 \%$ in MDA-MB-468 cells; $22 \pm 1.8 \%$ in MDA-MB-231 cells, compared with $11 \pm 1.2 \%, 12 \pm 1.3 \%$, $10 \pm 1.2 \%$, of Annexin-positive cells detected in untreated cells respectively (Table 2 ).
Results are representative of at least three independent experiment, The CELL Quest software application was used to examine the results. When the relevant values were compared to each other, the results were statistically significant (Annexin-positive cells detected in treated cell lines versus Annexin-positive cells detected in untreated

Table 2. Percentage of Annexin-Positive Cells in Urtica Dioica-Treated Cell Lines The Means \pm Standard Error is Used to Denominate the Results. $(\mathrm{p}<0.05)$ was used as the statistical significance level

\begin{tabular}{lccc}
\hline & MCF-7 & MDA-MB-468 & MDA-MB-231 \\
\hline In untreated control cell lines & $11 \pm 1.2 \%$ & $12 \pm 1.3 \%$ & $10 \pm 1.2 \%$ \\
In Urtica Dioica treated cell lines & $21 \pm 2.3 \%$ & $23 \pm 2.3 \%$ & $22 \pm 1.8 \%$ \\
& $(\mathrm{p}=0.002)(\mathrm{p}<0.05)$ & $(\mathrm{p}=0.002)(\mathrm{p}<0.05)$ & $(\mathrm{p}=0.002)(\mathrm{p}<0.05)$ \\
\hline
\end{tabular}

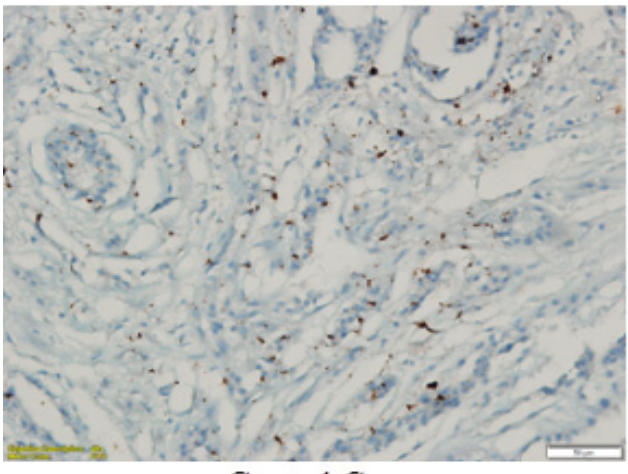

a. Control Group

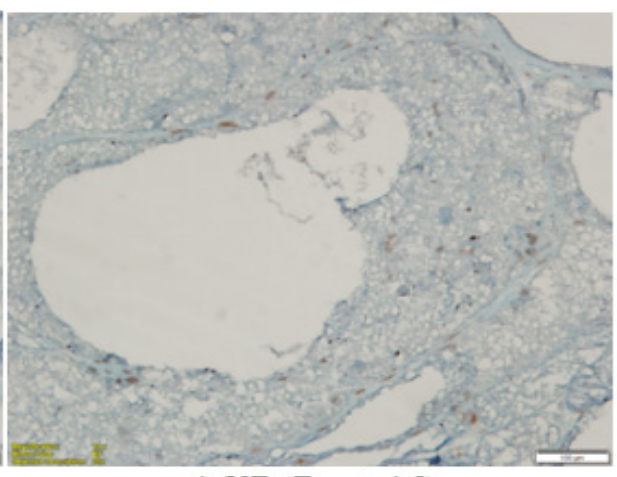

b.UD Treated Group

Figure 2. Ki-67 Immunohistochemistry Investigations on DMBA-Induced Breast Tumor Tissue of Rrats in the UD Group (a). Ki-67 expression was lower in the UD-treated group (b) than the untreated control group $(\mathrm{p}<0.05)$. 


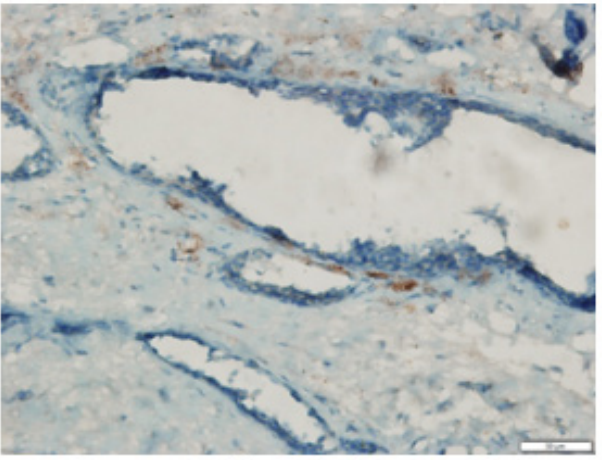

a. Control Group

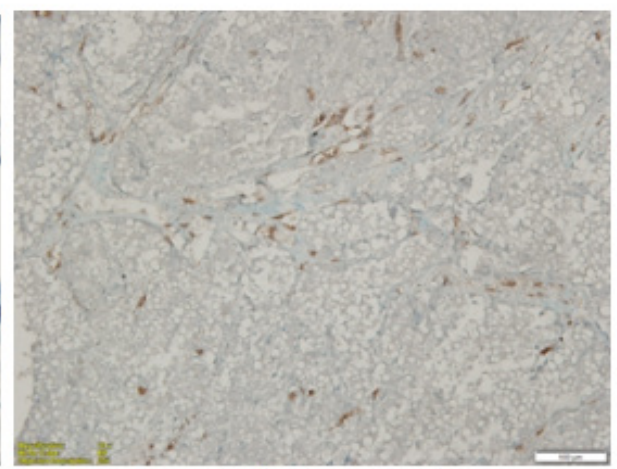

b.UD Treated Group

Figure 3. Caspase-3 Expression in Breast Tumor Cells in UD Used Treated Group in a DMBA-Induced Rat Mammary Animal Model (b). The expression is at its highest point and is higher than that of the Untreated Control Group (a) $(\mathrm{p}<0.05)$.

Table 3. The Semiquantitative Scoring System was Used to Determine the Results of Immunohistochemical Studies. The mean \pm S.E. $(p<0.05)$ was used to calculate the results (Mann-Whitney U test)

\begin{tabular}{lcccc}
\hline Immunohistochemical Studies & Ki- 67 & Caspase 3 & $\mathrm{p} 53$ & TUNEL staining \\
\hline In Urtica Dioica treated rats & $1,30 \pm 0,08^{*}$ & $2,82 \pm 0,07$ & $3,21 \pm 0,05$ & $2,89 \pm 0,12$ \\
In untreated control rats & $2.45 \pm 0,09$ & $1,21 \pm 0,19$ & $1,32 \pm 0,09$ & $1,22 \pm 0,17$ \\
Statististical results & $\mathrm{P}=0.003(\mathrm{p}<0.05)$ & $\mathrm{P}=0.002(\mathrm{p}<0.05)$ & $\mathrm{P}=0.002(\mathrm{p}<0.05)$ & $\mathrm{P}=0.002(\mathrm{p}<0.05)$ \\
\hline
\end{tabular}

cells). These findings revealed that UD treatment induces apoptosis in MCF-7, MDA-MB-468, and MDA-MB-231 cells.

\section{Immunohistochemical Experiments}

Each tumor tissues were sampled macroscopically and fixed. Ki-67 and p53 parameters were studied as immunohistochemically methods. Figures 2, 3, 4 and 5 indicate the results. All these results were statistically compared using The Semiquantitative Scoring System (Table 3).

Table 4. The Use of UD as a Treatment When the Tumor Volume Reached $250 \pm 6 \mathrm{~mm} 3$, the Patient was Placed in (Group II). No treatment was given to the control group (Group I). The Tumor Volume Inhibition Ratio (\%) was calculated as follows: Inhibition Ratio $(\%)=[(\mathrm{A}-\mathrm{B}) / \mathrm{A}] \mathrm{x} 100$, where A is the Control Group's Average Tumor Volume and B is the Treated Group's Tumor Volume. The Mean Tumor Volume \pm Standard Error $(\mathrm{mm} 3)(\mathrm{p}<0.05)$ was used to calculate the results

\begin{tabular}{lccccccc}
\hline & Beginning & 1 st week & 2nd week & 3rd week & 4th week & 5th week & 6th week \\
\hline UD Used Treated Group & $251 \pm 7,2^{*}$ & $307 \pm 7,6$ & $421 \pm 6,8$ & $670 \pm 5,1$ & $710 \pm 5,9$ & $789 \pm 6,8$ & $881 \pm 8,1$ \\
Control Group & $250 \pm 5,4$ & $340 \pm 5,2$ & $510 \pm 7,4$ & $820 \pm 6,4$ & $1020 \pm 5,4$ & $1270 \pm 6,4$ & $1430 \pm 7,2$ \\
The Tumor Volume Inhibition Ratio (\%) & - & 9 & 17 & 18 & 30 & 37 & 38 \\
Statistical findings & - & $\mathrm{P}=0.003$ & $\mathrm{P}=0.003$ & $\mathrm{P}=0.002$ & $\mathrm{P}=0.002$ & $\mathrm{P}=0.002$ & $\mathrm{P}=0.002$ \\
& & $(\mathrm{p}<0.05)$ & $(\mathrm{p}<0.05)$ & $(\mathrm{p}<0.05)$ & $(\mathrm{p}<0.05)$ & $(\mathrm{p}<0.05)$ & $(\mathrm{p}<0.05)$ \\
\hline
\end{tabular}

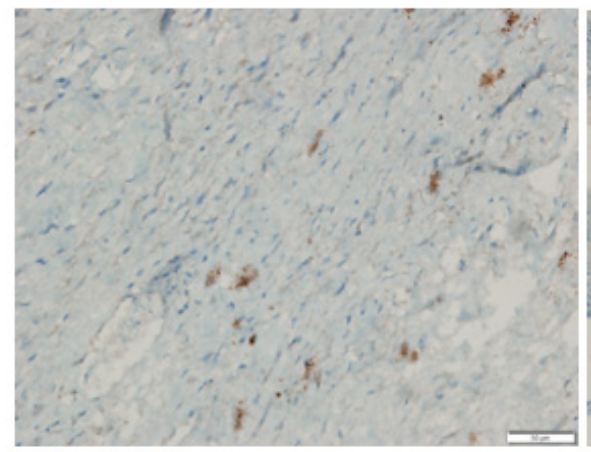

a. Control Group

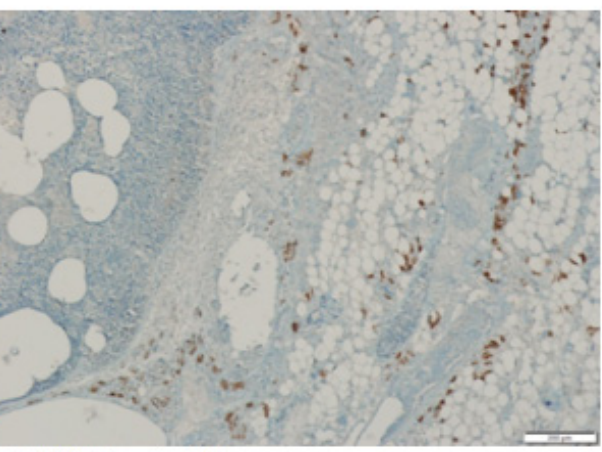

b.UD Treated Group

Figure 4. In the DMBA-induced Rat Mammary Animal Model, p53 Expression in Breast Tumor CCells Treated with UD Extract is Higher than the Untreated Control Group $(p<0.05)$. 


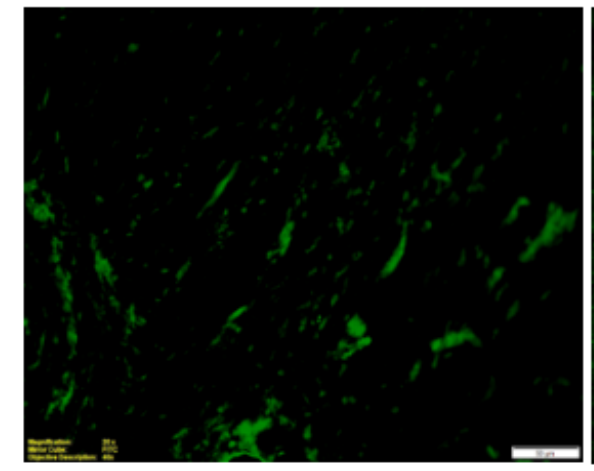

a.Control Group

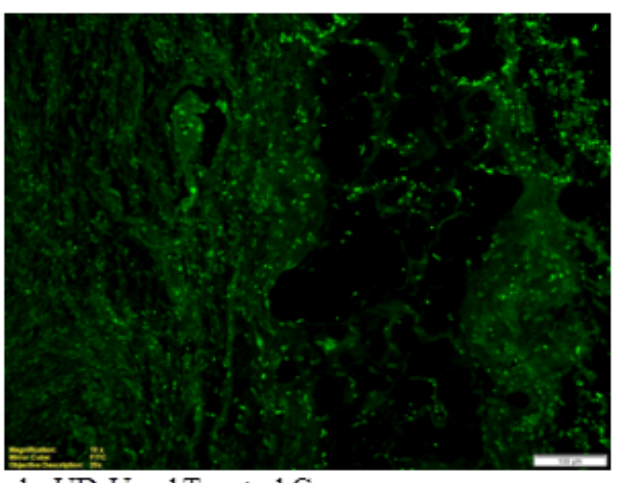

b. UD Used Treated Group

Figure 5. TUNEL-Positive Apoptotic Cells in DMBA-Induced Rat Mammary Tumor Tissue are Shown in Immunohistochemical Photomicrographs. In the Urtica Dioica treated group (b), numerous TUNEL positive cells were tracked in detail compared to the untreated control group (a) $(\mathrm{p}<0.05)$.

\section{Tumor volume studies}

When compared to the untreated rats (Group I), the mean tumor volume inhibition ratio in the UD-treated animals (Group II) was 38\% after 6 weeks of treatment (Table 4, Figure 6). All of the variations in tumor volume inhibition ratio between the treatment and control groups were statistically significant $(\mathrm{p}<0.05)$ (Table 4$)$. In all of the treated rats, there were no evidence of toxicity (weight loss, ruffled fur, or behavioral abnormalities) (Group II).

\section{Discussion}

Phytochemicals are employed in the prevention and treatment of cancer. Many plant species' medicinal

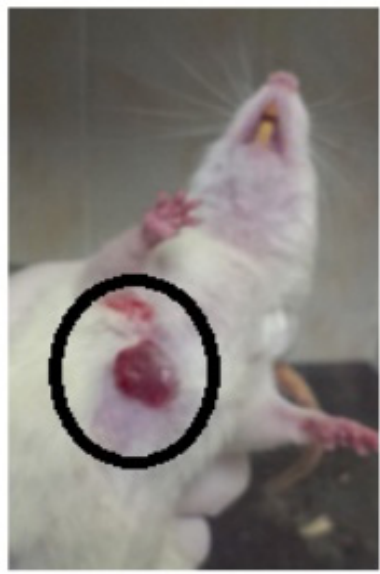

।

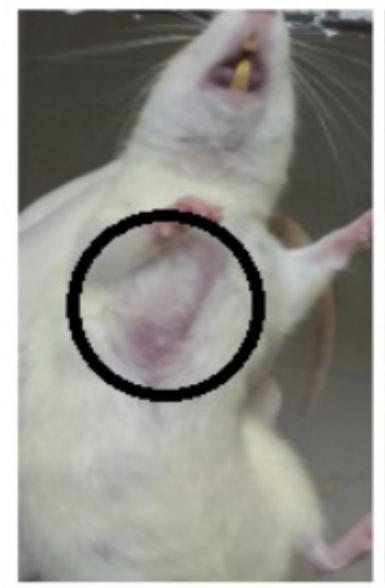

d.

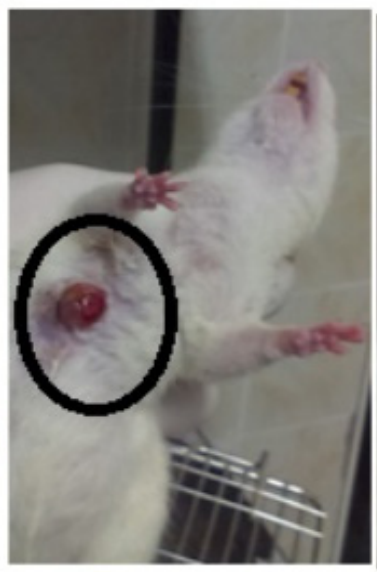

b.

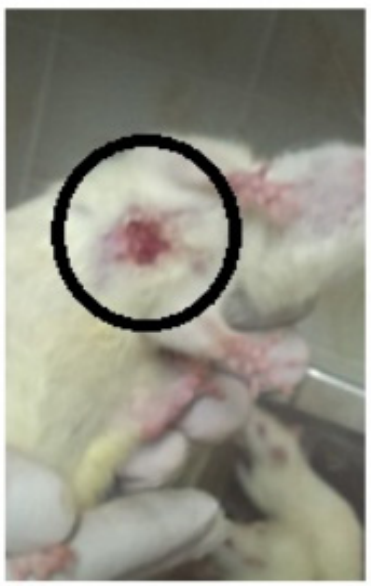

e.
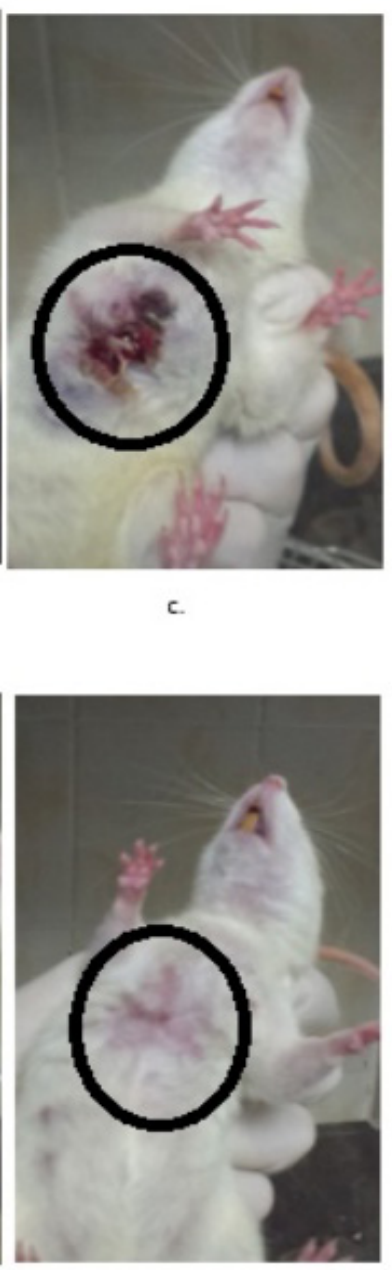

f.

Figure 6. DMBA-Induced Mammary Tumor Model in Rats. The tumoral masses are demonstrated by circles. The UD-treated rats are indicated in the Figures d, e, and $\mathrm{f}$ while the untreated control rats are indicated in the Figures a, $\mathrm{b}$, and $\mathrm{c}$. 
properties are thought to be attributable to the presence of antioxidative phenolics in their tissues. These chemicals may operate as plant pigments while simultaneously acting as a plant defense mechanism against UV radiation, insects, and microorganisms (Di Maro et al., 2013; Pacifico et al., 2015), Phenols and polyphenols found in food have received a lot of interest as therapeutic and preventive agents for chronic and degenerative disorders (Del Rio et al., 2013; Pacifico et al., 2015).

Urtica Dioica is a plant that has been used medicinally for a long time. Modern study and scientific proof have validated some of Urtica Dioica's therapeutic properties. The benefits of UD may be linked to its diversity in secondary metabolites, and its content appears to be heavily impacted by geographic conditions, as well as taxonomic, morphological, and genetic characteristics (Farag et al., 2013). A lot of research have focused on it and confirmed that UD is a good source of flavonoids and phenylpropanoids (Upton et al., 2013).

Urtica consumption has been linked to a reduction in cancer-related fatalities, according to several epidemiological research. UD has been shown to have anti-mutagenic properties (Di Sotto et al., 2015). Superoxide-radical scavenger assays and investigation of changes in antioxidant enzymes were used to report the anti-oxidant and radical scavenging activities of U. Dioica (Bisht et al., 2017; Fattahi et al., 2013).

The cytotoxic effects of an ethanolic extract of UD roots on human colon (HT29) and stomach (MKN45) cancer cells were demonstrated in a study (Ghasemi et al., 2016). In this study the cytotoxic activity of UD was tested by Trypan blue dye exclusion test and MTT assay. UD was detected to be cytotoxic to three cancer cell lines, with IC50 values of $18 \mu \mathrm{g} / \mathrm{mL}$ in MCF-7 cells, $17 \mu \mathrm{g} / \mathrm{mL}$ in MDA-MB-468 cells, and $14 \mu \mathrm{g} / \mathrm{mL}$ in MDA-MB-231 cells. These findings demonstrated that UD extracts had cytotoxic activity against breast cancer cell lines.

Effective cancer treatment necessitates the stimulation of apoptosis in cancer cells, which results in the controlled death of malignant and damaged cells without causing harm to normal dividing cells. The format (Annexin V-FITC) is used as a sensitive probe for flow cytometric detection of apoptotic cells (Vermes et al., 1995). Annexinpositive cells were discovered by flow cytometry in UD-treated cell lines at a rate of $21 \%$ in MCF-7 cells, $23 \%$ in MDA-MB-468 cells, and 22\% in MDA-MB-231 cells (Table 2), compared to $11 \%, 12 \%$ and $10 \%$ of Annexin-positive cells observed in untreated cancer cells, respectively. As a result of this assay, it was discovered that UD Used Treatment Group's extract caused apoptosis in breast cancer cells.

A set of proteases is triggered during apoptosis, causing DNA fragmentation, cytoplasmic shrinkage, and membrane blebbing. Using the TUNEL technique, we investigated apoptosis in tumoral tissues. This study's TUNEL Assay results showed that UD extracts administration increased the number of apoptotic cells in tumoral tissues of UD-treated rats.

When cells are determined to die by apoptosis, they indicate some biochemical (DNA fragmentation, phosphatidylserine translocated to the outer leaflet of apoptotic cell membranes) and morphological changes (cell shrinkage, chromatin condensation, apoptotic bodies) after indicating for apoptosis. These changes can be determined by means of various methods. DNA fragmentation can be explicitly determined by histochemical (TUNEL) (Unver Saraydin et al., 2020).

Antigen Ki-67 is a nuclear protein linked to cell proliferation, and it's a good way to figure out what percentage of a cell population is growing. The percentage of Ki-67-positive tumor cells is frequently linked to the progression of cancer. In univariate and multivariate analysis, the predictive significance for survival and tumor recurrence for prostate, brain, and breast carcinomas has been consistently demonstrated (Bullwinkel et al., 2006). To investigate the effect of UD on tumor growth, we looked at the Ki-67 levels in DMBA-induced tumoral tissues. The UD extract administration reduced Ki-67 activity in tumoral tissues of rats, according to in vivo immunohistochemical investigations conducted in this study.

The caspase family of highly conserved cysteine proteases play an essential role in apoptosis. Mammalian caspases can be subdivided into three functional groups: initiator caspases (Caspase 2, 8, 9 and 10), executioner caspases (Caspase 3, 6 and 7), and inflammatory caspases (Caspase 1, 4, 5, 11 and 12) (Shin et al., 2001). Caspase-3 is a protein that is involved in apoptosis, or programmed cell death. Caspases 8, 9, and 10 process the executioner Caspases 3 and 7 once activated. Caspases 3 and 7 mature to cleave a wide range of substrates, resulting in the morphological and biochemical hallmarks of apoptosis (Shin et al., 2001). This study's in vivo immunohistochemical studies revealed that the UD extract treatment activated Caspase-3. These findings could indicate that UD triggered apoptosis in breast cancer cells via the caspase pathway.

The p53 gene produces a protein that controls cell division. In response to genotoxic or cellular stress, it regulates the expression of many genes involved in apoptosis, growth arrest, or senescence. To investigate the effect of UD on tumor growth, we looked at the p53 levels in DMBA-induced tumoral tissues. The UD extract administration boosted p53 activity in tumoral tissues of rats in this study's in vivo immunohistochemical investigations.

Treatment with UD inhibited tumor volume by 38 percent in rat mammary tumor volume tests produced by DMBA. This is a statistically significant difference $(p<0.05)$. This finding demonstrated the ability of UD extract to prevent tumor growth.

The presence of flavonoids and other recognized compounds, as well as still unknown compounds, is the most plausible explanation for UD's significant anti-cancer action. Flavonoids are polyphenolic chemicals that might generate anti-cancer benefits through several methods including as antioxidant activity, induction of apoptosis, suppression of cell development, and cell migration, among the dietary bioactive molecules of UD.

Limitation of the study is in collection and preparation of the Urtica Dioica extracts. In future we are planning to study the exact major subcomponents of this crude 


\section{UD extract.}

As a result of these findings, natural UD extract appears to be a viable anticancer agent in the treatment of breast cancer. Several chemicals could, however, be responsible for the reported effects. For the further studies to comprehend this plant's various anti-cancer effects and explore these potentials in the battle against human diseases, more research is required to extract and describe the pure bioactive chemicals taking place in it.

\section{Author Contribution Statement}

The authors confirm contribution to the paper as follows: Study conception and design: Percin Karakol, Mustafa Turan and Mehmet Bozkurt; data collection: Percin Karakol, Mustafa Turan, Serpil Unver Saraydin, Ceylan Hepokur; analysis and interpretation of results: Mustafa Turan, Mehmet Bozkurt, Zeynep Deniz Sahin Inan; draft manuscript preparation: Percin Karakol and Ceylan Hepokur. All authors reviewed the results and approved the final version of the manuscript.

\section{Acknowledgements}

\section{Funding Statement}

This work has been supported by the Scientific Research Project Fund of Bagcilar Education and Training Hospital, Istanbul.

\section{Conflict of interest}

The authors have declared that there is no conflict of interest.

\section{References}

Abu-dahab R, Afifi F (2007). Antiproliferative activity of selected medicinal plants of Jordan against a breast adenocarcinoma cell line (MCF7). Scientia Pharmaceutica, 75, 121-36.

Akbay P, Basaran AA, Undeger U, Basaran N (2003). In vitro immunomodulatory activity of flavonoid glycosides from Urtica dioica L. Phytother Res, 17, 34-7.

Bisht R, Joshi BC, Kalia AN, Prakash A (2017). Antioxidantrich fraction of urtica dioica mediated rescue of striatal mito-oxidative damage in MPTP-induced behavioral, cellular, and neurochemical alterations in rats. $\mathrm{Mol}$ Neurobiol, 54, 5632-45.

Bullwinkel J, Baron-Lühr B, Lüdemann A, et al (2006). Ki-67 protein is associated with ribosomal RNA transcription in quiescent and proliferating cells. $J$ Cell Physiol, 206, 624-35.

Del Rio D, Rodriguez-Mateos A, Spencer JP, et al (2013). Dietary (poly)phenolics in human health: structures, bioavailability, and evidence of protective effects against chronic diseases. Antioxid Redox Signal, 18, 1818-92.

Dhouibi R, Hanen A, Maryem BS, et al (2019). Screening of pharmacological uses of Urtica dioica and others benefits. Progress Biophys Mol Biol, https://doi.org/10.1016/j. pbiomolbio.2019.05.008.

Di Maro A, Pacifico S, Fiorentino A, et al (2013). Raviscanina wild asparagus (Asparagus acutifolius L.): A nutritionally valuable crop with antioxidant and antiproliferative properties. Food Res Int, 53, 180-8.

Di Sotto A, Mazzanti G, Savickiene N, et al (2015). Antimutagenic and antioxidant activity of a protein fraction from aerial parts of Urtica dioica. Pharm Biol, 53, 935-8.
El Haouari M, Bnouham M, Bendahou M, et al (2006). Inhibition of rat platelet aggregation by Urtica dioica leaves extracts. Phytother Res, 20, 568-72.

Esposito S, Alessandro B, Rosita R, et al (2019). Therapeutic perspectives of molecules from urtica dioica extracts for cancer treatment. Molecules, 24, 2753.

Farag MA, Weigend M, Luebert F, Brokamp G, Wessjohann LA (2013). Phytochemical, phylogenetic, and anti-inflammatory evaluation of 43 Urtica accessions (stinging nettle) based on UPLC-Q-TOF-MS metabolomic profiles. Phytochemistry, 96, 170-83.

Fattahi S, Ardekani AM, Zabihi E, et al (2013). Antioxidant and apoptotic effects of an aqueous extract of Urtica dioica on the MCF-7 human breast cancer cell line. Asian Pac J Cancer Prev, 14, 5317-23.

Francišković M, Raquel G, Dejan O (2017). Chemical composition and immuno-modulatory effects of Urtica dioica L. (Stinging Nettle) extracts. Phytother Res, 2017. DOI: $10.1002 /$ ptr.5836.

Ghasemi S, Moradzadeh M, Mousavi SH, Sadeghnia HR (2016). Cytotoxic effects of Urtica dioica radix on human colon (HT29) and gastric (MKN45) cancer cells mediated through oxidative and apoptotic mechanisms. Cell Mol Biol (Noisy-le-grand), 62, 90-9.

Gözüm S, Tezel A, Koc M (2003). Complementary alternative treatments used by patients with cancer in eastern Turkey. Cancer Nurs, 26, 230-6.

Han CP, Kok LF, Wang PH, et al (2009). Scoring of p16(INK4a) immunohistochemistry based on independent nuclear staining alone can sufficiently distinguish between endocervical and endometrial adenocarcinomas in a tissue microarray study. Mod Pathol, 22, 797-806.

Kan Y, Orhan IE, Koca U, et al (2009). Fatty acid profile and antimicrobial effect of the seed oils Of Urtica Dioica and U. Pilulifera. Turk J Pharm Sci, 6, 21-30.

Mandal P, Misra TK, Singh ID, Das JK, Bhunia M (2009). Freeradical-scavenging activity in the inflorescence of European Nettle/Sisnu (Urtica dioica L.). J Young Pharmacists, 1, 129- 35 .

Mansoori B, Ali M, Shahriar H (2017). Urtica dioica extract suppresses miR-21 and metastasis-related genes in breast cancer. Biomed Pharm, 93, 95-102.

Martinez MJA, Benito PB (2005). Biological activity of quinones. Atta-Ur-Rahman (Ed.). Studies Nat Product Chem, 30, 303-66.

Pacifico S, Piccolella S (2015). Plant-derived polyphenols: A Chemopreventive and Chemoprotectant Worth-Exploring Resource in Toxicology. In Advances in Molecular Toxicology; Fishbein, J.C., Heilman, J.M., Eds.; Elsevier: Amsterdam, The Netherlands, 2015; pp. 161-214. 10.1016/j. phytochem.2013.09.016. Epub 2013 Oct 26. PMID: 24169378.

Pacifico S, Galasso S, Piccolella S, et al (2015). Seasonal variation in phenolic composition and antioxidant and antiinflammatory activities of Calamintha nepeta (L.) Savi. Food Res Int, 69, 121-32.

Roomi MW, Roomi NW, Bhanap B, Rath M, Niedzwiecki A (2011). In vivo and in vitro antitumor effects of nutrient mixture in murine leukemia cell line P-388. Exp Oncol, 33, 71-7.

Roschek B Jr, Fink RC, McMichael M, Alberte RS (2009). Nettle extract (Urtica dioica) affects key receptors and enzymes associated with allergic rhinitis. Phytother Res, 23, 920-6.

Saponaro M, Isabella G, Giulia M (2020). Serenoa repens and Urtica dioica Fixed Combination: In-Vitro Validation of a Therapy for Benign Prostatic Hyperplasia (BPH). Int J Mol Sci, 21, 9178 . 
Shin S, Sung BJ, Cho YS, et al (2001). An anti-apoptotic protein human survivin is a direct inhibitor of caspase-3 and -7 . Biochemistry, 40, 1117-23.

Tello S, Halifeoğlu I, Bozkurt M, et al (2008). Meme Kanseri Olusturulmus Ratlarda Isırgan Otunun Total Antioksidan Durumu Üzerine Etkisi. Fırat Üniversitesi Sağllk Bilimleri Tip Dergisi, 22, 179-83.

Toldy A, Atalay M, Stadler K, et al (2008). The beneficial effects of nettle supplementation and exercise on brain lesion and memory in rat. $J$ Nutr Biochem, 20, 974-81.

Upton R (2013). Stinging nettles leaf (Urtica dioica L.): Extraordinary vegetable medicine. J Herb Med, 3, 9-38.

Ünver Saraydin S, Saraydin D, Şahin İnan ZD (2020). A study of digital image analysis on the acrylamide derivative monomers induced apoptosis in rat cerebrum. Microsc Res Tech, 83, 436-45.

Vermes I, Haanen C, Steffens-Nakken H, Reutelingsperger C (1995). A novel assay for apoptosis. Flow cytometric detection of phosphatidylserine expression on early apoptotic cells using fluorescein labelled Annexin V. J Immunol Methods, 184, 39-51.

Wollowski I, Rechkemmer G, Pool-Zobel BL (2001). Protective role of probiotics and prebiotics in colon cancer. Am J Clin Nutr, 73, 451-5.

\section{cc) (i) (8)}

This work is licensed under a Creative Commons AttributionNon Commercial 4.0 International License. 